\title{
Obstetricians on the labour ward: implications of medical staffing structures
}

\author{
V A COUPLAND，J M GREEN, J V KITZINGER， M P M RICHARDS
}

The 1981 Short report on medical education in Britain recommended changes in the medical career structure. ${ }^{1}$ Many other reports have addressed the fundamental problem associated with the traditional three tier structure of the consultant led team consisting of consultants, registrars, and house officers. In essence this problem arises from two conflicting requirements: the need to provide training in the context of a reasonable career structure while ensuring that patients are treated by fully qualified staff. From time to time targets for numbers of consultants and junior doctors designed to meet these conflicting needs have been set but never met. The inertia of the established organisation and practices and the resistance from those directly concerned have been too great to allow change.

The Short report recommended an increase in the number of consultants and a reduction in the number of junior doctors in most hospitals and in most specialties; that the supply of senior registrars should keep pace with the increase in the number of consultants; and that all senior house officer posts should be frozen.

In practice the Short report's recommendations have been interpreted to mean that in most district (non-teaching) hospitals medical staffing would be two tier and consultant based-that is, with only consultants and senior house officers. Registrars would be confined to specified training posts, usually in teaching hospitals. To permit such a pattern there would be a large increase in the number of consultants, who would share the routine work now generally carried out by registrars. In obstetrics this would include most forceps deliveries and caesarean sections.

The proposed change from three tier consultant led to two tier consultant based staffing has been resisted by consultants, who are particularly opposed to reducing the number of registrars and senior house officers. ${ }^{23}$ Opposition has been strong among obstetricians, many of whom object to having to return to unsociable on call hours and night duty emergency work. ${ }^{4}$

We investigated the practical effects of the Short report's proposals for labour ward staff-doctors and midwives-and this paper concentrates on the implications for obstetric consultants. The important effects on junior doctors and midwives are dealt with in a paper yet to be published and in a detailed report of this research.

\section{Methods}

Six obstetric units were examined, three working with registrars and three without. Only one of the two tier units had been deliberately set up on Short principles; the two others worked

Department of Paediatrics and Social and Political Sciences Committee, University of Cambridge, Cambridge CB2 3RF

V A COUPLAND, BA, research assistant

J M GREEN, BA, PHD, senior research associate

J V KITZINGER, BA, research assistant

M P M RICHARDS, MA, PHD, lecturer in social psychology

Correspondence to: Ms V A Coupland, Child Care and Development Group, Department of Paediatrics and Social and Political Sciences Committee, University of Cambridge, Free School Lane, Cambridge CB2 3RF without registrars for historical, financial, and practical reasons. All of the units were in district hospitals.

The table shows the medical staffing and the number of deliveries in 1985 for each unit.

Medical staffing and number of consultant unit deliveries in 1985 in each of six study hospitals

\begin{tabular}{lcccccc}
\hline Unit & $\begin{array}{c}\text { No of } \\
\text { deliveries }\end{array}$ & $\begin{array}{c}\text { No of } \\
\text { consultants }\end{array}$ & $\begin{array}{c}\text { No of } \\
\text { registrars } \\
\text { or acting } \\
\text { registrars }\end{array}$ & $\begin{array}{c}\text { No of } \\
\text { senior } \\
\text { house } \\
\text { officers }\end{array}$ & $\begin{array}{c}\text { No of } \\
\text { deliveries } \\
\text { per } \\
\text { consultant }\end{array}$ & $\begin{array}{c}\text { No of } \\
\text { deliveries } \\
\text { per senior } \\
\text { doctort }\end{array}$ \\
\hline Two tier: & 1742 & 4 & & & & \\
A & 2124 & 3 & & 3 & 436 & 436 \\
C & 573 & 2 & & 2 & 708 & 708 \\
D & 2744 & 3 & 3 & 5 & 287 & 287 \\
Three tier: & 2446 & 3 & 3 & 6 & 915 & 457 \\
B & 2026 & 3 & 2 & 3 & 675 & 408 \\
E & F & & & 2 & & 405 \\
\hline
\end{tabular}

*One of the senior house officer posts at hospital $\mathrm{C}$ was always filled by a senior, experienced senior house officer. All other senior house officers in two tier hospitals were general practitioner trainees, as were 11 out of 14 in the three tier hospitals.

tConsultants, registrars, and acting registrars.

We used a combination of qualitative and quantitative methods. We interviewed midwives and midwifery managers and all grades of doctors: 44 doctors (including all 18 consultants) and 59 midwives were interviewed individually. A further 30 midwives and junior doctors were interviewed in small groups. The interviews were semistructured, lasting between half an hour and two and a half hours. In addition, there were over 400 hours of observation, nearly half of this at nights and weekends. Consultants and registrars kept on call diaries, designed to gauge the nature and frequency of night and weekend work under each staffing structure. Finally, statistics for the labour wards in each hospital were reviewed for evidence of a relation between staffing structure and obstetric outcome.

An additional four units were identified from the Royal College of Obstetricians and Gynaecologists' list of approved hospital posts as not having registrars. ${ }^{6}$ Telephone interviews were carried out with the head of the midwifery department (or equivalent) and senior consultant at each of these hospitals. Only one of these was functioning as a genuine two tier unit, the others having sufficient experienced senior house officers to operate a middle grade ( $\mathrm{J} M$ Green $e t$ al, unpublished observations). The information obtained from this one unit supported the data from the two tier units studied.

\section{Results}

\section{CONSULTANT'S ROLE IN THE TWO TIER STRUCTURE}

The consultants' role on the labour ward changes dramatically when there is no registrar. Consultants in the two tier hospitals spent much more time on the labour ward carrying out "hands on" practical procedures commonly performed by registrars in three tier units; they were also more closely concerned with the supervision 
and training of senior house officers. Without a registrar it is clearly necessary for the consultant to be in much closer touch with the progress of individual women who develop complications during or after delivery. Consequently there was much less reliance on written policy to dictate courses of action by junior medical staff and midwives. This allowed more direct and personal communication between consultants and midwives in the two tier units. They were, on the whole, more relaxed with each other and had more confidence in each other's skills and experience. An outstanding feature of the consultants in the two tier hospitals was their respect for and knowledge of the midwives' abilities. This contrasted sharply with the lack of respect on the part of many of the consultants in the three tier hospitals. Furthermore, some of the consultants in the two tier hospitals were making concerted efforts to extend the midwife's role, safeguard her autonomy, and limit medical intervention in normal childbirth. Such an attitude is to the consultant's advantage, particularly at nights and weekends, when midwives are the most senior and experienced staff on the labour ward.

\section{NIGHTS}

Much of the concern and discussion about the recommendations for the two tier structure as they would affect obstetrics has centred on what happens at night and the vexed question of consultants sleeping in when on call.

Opponents of the consultant based two tier staffing structure have argued that this system in essentially unworkable, impractical, and even dangerous, particularly as a consultant gets older and the demands of working without a registrar take a toll on his or her health. ${ }^{711}$ The two tier staffing structure is unpopular, if for no other reason because of the unsocial and demanding on call and night duty hours, usually relinquished by a doctor once he or she reaches consultant status.

Accordingly, the practicalities of out of hours emergency work were carefully explored in interviews with the consultants in the study.

The consultants in both types of hospital strongly objected to sleeping in - that is, being resident on site when on call-and many junior doctors, imagining their own lives five, 10, and 15 years ahead, also saw this as an unacceptable development.

Of the nine consultants in two tier hospitals in the study, only one chose to sleep in as a matter of course. Another nine consultants in both types of structure occasionally slept in when called to the hospital late at night-perhaps a few times a year. So sleeping in was not an option taken up by consultants in the two tier hospitals. The midwives affirmed, however, that, with the exception of one individual, consultants came to the hospital quickly for emergencies.

\section{ON CALL DIARIES}

To supplement the data from interviews and observations consultants and registrars were asked to keep labour ward on call diaries over several weeks. These recorded each occasion on which the doctor was contacted out of hours. For each contact the reason, the caller, and the resulting action were recorded.

Although initially all the consultants and registrars agreed to keep diaries, the consultants in the two tier hospitals responded much better than those in the three tier system. Naturally we would have preferred more complete data from traditionally staffed hospitals, but the good response from two tier units was important as discussion and criticisms have tended to focus on what happens at night in these hospitals.

Consultants were asked to estimate how often they were contacted when on call. These estimates were then compared with the rates recorded in the diaries. Consultants in two tier units found it hard to make estimates but in general thought that they were contacted once or twice a night when on call-roughly the same estimates as those given by the consultants in the three tier hospitals. The diaries show that the estimates of the consultants in the two tier units matched fairly closely the rates they recorded. On most nights they were contacted one to three times, while on busy nights they were w్ disturbed as frequently as the registrars in three tier hospitals-up 3 to five or six times.

Consultants in three tier hospitals reported that they were usually $c$ contacted at least once when on call, generally by a prearranged $\widehat{\widehat{C}}$ telephone call or during a ward round. Nights without calls, apart $\bar{\Xi}$ from these routine contacts, were not uncommon and were probably the norm for the older consultants.

The main difference between consultants in the two tier and three tier hospitals in their out of hour experiences was not how often they were contacted when on call but how often they went into the hospital from home. It is difficult to give precise figures because whereas some consultants went in only when specifically requested, others would drop in informally when they happened to be passing by. The diaries, however, show that consultants in the two tier hospitals went in between one and eight times a month, with an average of 3.5 times. This was much more often than the consultants $\mathscr{\omega}^{\circ}$ in the three tier hospitals, who went in infrequently. There were $\vec{\circ}$ exceptions, as the diary of one consultant in a three tier system showed: he was contacted and went in about as often as the $\vec{\omega}$ consultants in two tier hospitals and did not consider his out of hour commitments onerous.

Two important factors influenced how often the consultant went on to the labour ward: the frequency of being on call, which was of determined by the number of consultants, and the likelihood of being contacted, which was determined by the on call rota in of operation and the workload. A wide variation in workload was a $\vec{P}$ feature in the six units. At one two tier hospital with a much higher ratio of births to consultants the consultants went in considerably $ᄋ$ more often than those at the other two tier units. This hospital had a ratio of 708 births per senior doctor, which is substantially higher $A$ than the guidelines from the Royal College of Obstetricians and Gynaecologists. $^{2}$

Consultants in two tier hospitals emphasised that adequate $\underset{\mathbb{D}}{\mathbb{D}}$ staffing was an essential factor in determining how effective and practical the two tier system might be. The critical point was that $\infty$ with a sufficient number of consultants to share the rota and allow time off in lieu, getting up at night need not become too arduous.

\section{PERCEPTION OF THE CONSULTANT'S ROLE}

It became clear that there were two distinct approaches to the role of consultant in obstetrics, that of obstetric unit manager and that of skilled practitioner. The managers saw their role as expert advisers and policy makers, with only minimal participation in labour ward emergencies. Their view was that the consultant's role was downgraded in a two tier structure because it included registrar type duties that they sometimes characterised as trivial work. Practitioner consultants, on the other hand, saw themselves as highly skilled technicians who had a responsibility to use the skills that had taken so long to acquire. Their emphasis was on active hands on labour ward procedures, which were much more compatible with two tier working.

The consultants with the managerial approach worked primarily in the three tier units, while those with the practitioner approach were usually in two tier units. To an extent this was a consequence of self selection. Some consultants in two tier units, however, who had not chosen to work this way had re-evaluated their role in the light of their experience. Others had not changed their views. One manager consultant in a two tier hospital had not adapted to the system at all but with the cooperation of his colleagues and a senior senior house 6 officer continued working like a consultant in a traditional three tier unit.

Job satisfaction in the two tier system was related to the consultant's initial and developing self perception as practitioner or manager. Certainly practitioners thought that their jobs entailed a great deal of hard work and that a firm commitment to the two tier structure was vital. They saw it as unwise to impose the two tier structure on unwilling staff because it might then become dangerous, but they argued that many of the personal difficulties associated with the two tier system were justified because of the benefit to patients and their own job satisfaction. 


\section{DHSS reviews category 2 work}

The Department of Health has published its long awaited review of category 2 work $^{\star}$ and sent it for consultation to health authorities and representatives of users of category 2 work as well as to the Central Committee for Hospital Medical Services. Consultation will take place until the end of the year-the CCHMS will recall its category 2 working party-and any changes proposed will be negotiated in the senior side of the Joint Negotiating Committee.

The department recommends:

- The section on category 2 in the Handbook on the Management of Private Practice should be amended to ensure that authorities apply the same control mechanisms to category 2 work as to private practice generally. For example, there should be a single mechanism for ensuring the proper identification of the status of work

- The mechanisms used to identify the status of work should apply to work submitted by general practitioners as well as by hospital doctors

- Hospital charges arising out of category 2 work

${ }^{\star}$ Category 2 work is presently defined in paragraph 37 of Hospital Medical and Dental Staff (England and Wales): Terms and Conditions of Service. It covers examinations and reports for which charges may be made (subject to the list of duties that are part of an NHS doctor's duties (category 1) described in paragraph 36). Examples are: reports on patients not under observation or treatment in hospital when the report is requested; examinations of patients referred by medical boards; and examinations and reports for life insurance. should be determined in accordance with the cost of the facilities used

- Hospital charges should always be collected by the health authority concerned either from the doctor or, together with the doctor's professional fee and with his agreement, from the individual or third party commissioning the work

- Health departments should consult with interested parties on the best means of dertermining such hospital charges.

\section{- \\ NHS managers' "letter" to the Secretary of State}

Emphasising that it wants to ensure the continued development and improvement of an excellent and cost effective public service, the Institute of Health Services Management has asked the new Secretary of State for Social Services, Mr John Moore, to bear in mind the following points.

- The proportion of the nation's wealth spent on health should be increased

With limited resources not all priorities could be achieved and the service needed a national debate to guide management at local levels

- New policies, such as the internal market, should not foster inequity or lead to inadequate health services

When testing the cost effectiveness of the service by competitive tendering he should realise that the remaining potential savings represented only a small percentage of district health authorities' budgets
A more satisfactory and explicit policy for dealing with pay and price inflation was needed

- To staff essential services better pay and better conditions and local flexibility were needed for the staff

- The answer to the NHS's problems was not another restructuring.

\section{Junior members forum}

The 1988 BMA junior members forum will be held on 9 and 10 April at the Stakis Grand Hotel, Stoke on Trent. The forum will be chaired by Dr Fay Wilson, a general practitioner in Sutton Coldfield.

The theme of the symposium on the first day will be the formation and future of the NHS. The speakers will include Miss Madeleine Halliday, from Health Rights; Dr Michael Goldsmith, a general practitioner; and $\mathrm{Mr}$ Nick Bosanquet, senior research fellow, University of York.

The second day (10 April) will be devoted to medicopolitics. One of the BMA's senior elected officers will address the meeting, and there will be reports from the forum's representatives on the council and the representative body. Motions on any subject arising from the reports of the previous day's symposium that have been tabled during or before the meeting will be debated. Motions from the forum are referred to the council, standing committees, and the representative body.

On the Saturday evening there will be a formal dinner with local BMA divisions.

BMA members who are under 40 and within 12 years of registration may obtain further details about the forum from regional offices.

\section{Talking point-continued from $p 1078$}

\section{OBSTETRIC PERFORMANCE}

Statistics for the labour wards at all six hospitals were examined for evidence of any systematic differences between two tier and three tier units. Data were analysed for the last complete year available (1985) and when possible for the previous three years as well. It was difficult to interpret the data because the information recorded by the hospitals varied. Given the small number of two tier units, it is not possible to say anything about the relative safety of this form of staffing. All the study hospitals had perinatal mortality rates of around or below the national average. Morbidity statistics were not routinely available.

The six hospitals were compared in terms of rates of caesarean sections (both elective and emergency), inductions, augmentation of labour, and instrumental deliveries. There were differences between individual hospitals, but these were not associated with staffing structure. There was great variation between the three two tier units. This may reflect the non-traditional approaches that consultants in these units were likely to endorse.

\section{Conclusion}

As might be expected, the two tier system demands more of consultants in terms of labour ward work and implies a change in the nature of the consultant's role. For those who saw themselves primarily as skilled practitioners this was perceived to be an advantage of the system that gave greater job satisfaction. The obvious weakness of two tier staffing is that additional consultants may not be appointed to compensate for missing registrars. This results in an unnecessarily onerous workload and allows insufficient slack in the system for time off after nights on call.
The two tier structure is not necessarily the solution for obstetric medical staffing. The system is demonstrably workable, though appropriate consultant attitudes are vital if it is to work in practice. The Short report has already been superseded by further proposals to solve the staffing imbalance. ${ }^{12}$ Nevertheless, it highlighted the concept of working without registrars and supplied a justification for this, thereby prompting the possibility of changes in the style of management in labour wards. Some consultants would argue that such a change is better not only for them but also, more importantly, for the women in their care.

This research was funded by grants from the Nuffield Provincial Hospitals Trust and the Health Promotion Research Trust to Mr M J Hare, Dr D R Williams, and MPMR.

\section{References}

1 Social Services Committee. Fourth report. Medical education with special reference to the number of doctors and the career structure in hospitals. London: HMSO, 1981. (Short report.)

2 Royal College of Obstetricians and Gynaecologists. Consultative document. Report of the manpower advisory sub-committee of the Royal College of Obstetricians and Gynaecologists. London: RCOG, 1983

3 Shrank AB. Consultant led, not consultant based, service. Br Med f 1985;290:1665

4 Stride R. Consultant-only service threatens waiting hists. Hospital Doctor 1985;5:2.

5 Green J, Kitzinger J, Coupland V. The division of labour: implications of medical staffing structures for midwives and doctors on the labour ward. University of Cambridge: Child Care and Development Group, 1986.

6 Royal College of Obstetricians and Gynaecologists. List of recognised hospital appointments for training for the membership and diploma. London: RCOG, 1985.

7 McCaig J. Hospital staffing structure: ideas for the future. The Consultant 1985;9:8-10.

8 Houghton DJ. Is there another consultant lifestyle? Br Med f 1983;287:562.

8 Houghton DJ. Is there another consultant lifestyle? $\mathrm{BrMed} \mathcal{F} 1983 ; 287: 562$

9 Valentine BH. Is there another consultant lifestyle? Br Med J 1983;287:9
10 Wolfe MJ. Is there another consultant lifestyle? Br Med f 1983;287:691.

11 Stride R. Consultants' outcry at Short style NHS. Hospital Doctor 1986;6:1.

12 Department of Health and Social Security, Joint Consultants Committee, chairmen of regional health authorities. Hospital medical staffing: achieving a balance. London: DHSS, 1986. 